\title{
Diagnosis of systemic toxoplasmosis with HIV infection using DNA extracted from paraffin- embedded tissue for polymerase chain reaction: a case report
}

Yoichiro Okubo ${ }^{1}$, Minoru Shinozaki', Sadako Yoshizawa ${ }^{2}$, Haruo Nakayama ${ }^{1}$, Megumi Wakayama ${ }^{1}$, Tsutomu Hatori ${ }^{1}$, Aki Mituda', Takayuki Hirano', Kayoko Shimodaira', Zhi Yuzhu', Kazutoshi Shibuya ${ }^{\text {** }}$

\begin{abstract}
Introduction: Toxoplasmosis can be a life-threatening disease when it occurs in patients with HIV infection. In particular, meningioencephalitis has been regarded as the most common toxoplasmic complication in such patients. However, toxoplasmic meningitis in a patient with HIV infection is extremely rare and purulent or tuberculous meningitis should be considered initially as a disease for differential diagnosis in Japan.
\end{abstract}

Case presentation: Toxoplasmic meningitis in a patient with HIV infection is reported. A 36-year-old Japanese man presented with fever, pulsating headache, lumbago, nausea, and vomiting. No examinations suggested toxoplasmosis including cerebrospinal fluid examinations, images, and serological tests. The result of a polymerase chain reaction assay using paraffin-embedded section was regarded as the conclusive evidence for the diagnosis.

Conclusions: We wish to emphasize the usefulness of polymerase chain reaction assays with nucleic acid extracted from paraffin-embedded tissue sections processed for routine histopathological examination, if the section shows the infectious agents or findings suggesting some infectious diseases.

\section{Introduction}

Toxoplasma gondii is known as one of the most common infectious protozoan parasites that has a worldwide distribution [1-3]. Cats are recognized as the only definitive hosts of $T$. gondii, but humans can be infected by the ingestion of oocysts or tissue cysts [4]. T. gondii infection is generally asymptomatic or associated with lymphadenopathy and manifests as a flu-like illness in immunocompetent individuals. However, the infection causes severe and fatal complications, especially in the central nervous system, in immunocompromised individuals $[2,5]$. This paper describes a case of toxoplasmosis in patient with HIV infection that was diagnosed by polymerase chain reaction (PCR) with the use of nucleic acid extracted from formalin-fixed and paraffin-

\footnotetext{
* Correspondence: kaz@med.toho-u.ac.jp

'Department of Surgical Pathology, Toho University School of Medicine,

6-11-1 Omori-Nishi, Ota-Ku, Tokyo, 143-8541, Japan

Full list of author information is available at the end of the article
}

embedded tissue (bone marrow aspiration clot) sections prepared for routine histopathological examination.

\section{Case presentation}

A 36-year-old Japanese man with a 14-month history of HIV infection presented with fever, pulsating headache, lumbago, nausea, and vomiting four week prior to his admission. Although highly active anti-retroviral therapy (HAART) had been started (lamivudine, azidothymidine, and lopinavir plus ritonavir) after completion of treatment for pneumocystis pneumonia, which had been the initial clinical manifestation of our patient, his CD4-positive lymphocyte counts in peripheral blood has never recovered to more than 200 cells $/ \mathrm{mm}^{3}$. Therefore, three months before admission, abacavir was given instead of azidothymidine, but was also insufficient for increasing CD4-positive lymphocytes. Furthermore, according to the guidelines, prophylaxis against Pneumocystis jirovecii had been started. In our case, atovaquone had been administered, because sulfamethoxazole-trimethoprim 
and pentamidine had caused hepatic and renal insufficiency, respectively. On physical examination, our patient reported headache with neck stiffness. His axillary temperature was $38.2^{\circ} \mathrm{C}$. Chest radiography and computed tomography $(\mathrm{CT})$ of the brain showed no abnormalities. He was diagnosed as purulent meningitis, initially, because of an increasing of neutrophils count in cerebrospinal fluid (CSF). Broad-spectrum antimicrobials, however, had no effect on this meningitis. CD4-positive lymphocyte counts $146 / \mu \mathrm{l}$ in peripheral blood. He did not show increasing of immunoglobulin G (IgG) and immunoglobulin $M$ (IgM) fraction of anti-T. gondii antibody (enzyme-linked immunosorbant assay, ELISA). Three weeks after admission, due to worsened headache and lumbago, magnetic resonance imaging (MRI) of the brain and lumbar vertebrae was performed and showed enhanced small nodules at right superior pons and bilateral superior cerebellum, peripheral enhancement at the bilateral superior pons, and enhanced lesions which was parallel to left inner ear. These findings strongly suggested meningitis with granuloma formation, such as tuberculosis. Furthermore, MRI of the lumber vertebrae also suggested the presence of the granulomatous lesion. However, the PCR assay targeting mycobacterium tuberculosis was negative. Therefore, bone marrow aspiration biopsy was performed for histopathological examination to elucidate the causative agent of generalized infection. The specimen, bone marrow aspiration clot, was fixed with $10 \%$ formalin and embedded in paraffin wax after dehydration which was cut into $3 \mu \mathrm{m}$-thick sections, and routinely stained with hematoxylin and eosin double stain. Histopathological examination indicated hypocellular bone marrow in which clustered intra-cellular basophilic granuli were present (Figure 1). These were confirmed as microcalcification by Von Kossa's stain. Therefore, the PCR assay with toxoplasma-specific primer was performed using nucleic acid extracted from the formalin-fixed and paraffin-embedded tissue (bone marrow aspiration) section. In the procedure, paraffinembedded tissue sections (bone marrow aspiration clot) were deparaffinized by xylene and immersed in absolute ethanol. The air-dried pellets of dehydrated section were then resuspended in extraction buffer (Tris- $\mathrm{HCl}[50 \mathrm{mM}$, $\mathrm{pH}$ 8.5], $\mathrm{NaCl}$ [50 mM], EDTA [10 mM], sodium dodecyl sulfate $[0.5 \%]$, proteinase $\mathrm{K}[10 \mathrm{mg} / \mathrm{mL}])$ at $95^{\circ} \mathrm{C}$. The samples were completely submerged in the extraction buffer and incubated at $56^{\circ} \mathrm{C}$ for 12 hours. The supernatant was then purified by phenol-chloroform extraction and ethanol precipitation, and was resuspended in $25 \mathrm{~mL}$ of DNase-free buffer (Tris- $\mathrm{HCl}$ [10 mM], EDTA [1 $\mathrm{mM}]$ ), and was stored at $20^{\circ} \mathrm{C}$ until use for DNA amplification. PCR for B1 gene of $T$. gondii was carried out following the previous description of Tachikawa et al. [6]. The primers used in the assay are summarized in

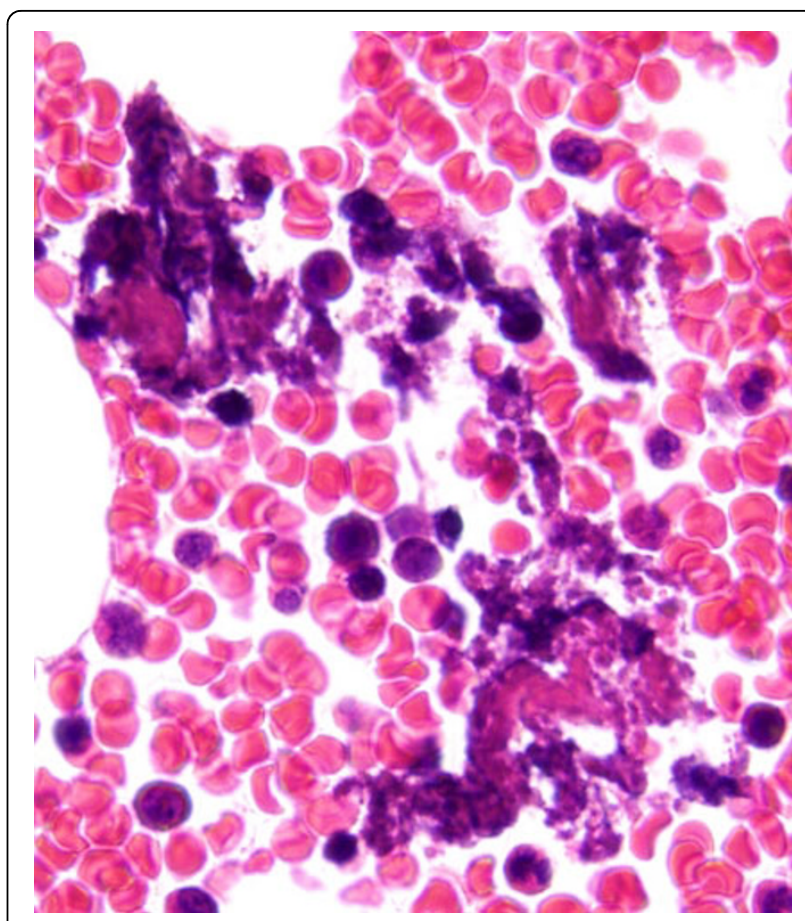

Figure 1 Hematoxylin and eosin stain of bone marrow. Hematoxylin and eosin stain of bone marrow. Clustered intracellular basophilic granuli suggesting toxoplasmosis was present (x1000).

Additional file 1. Conditions of nested PCR for T. gondii were $0.5 \mathrm{pmol} / \mathrm{L}$ primer, $2.5 \mathrm{mM} \mathrm{MgCl} 2,0.2 \mathrm{mM}$ dNTP, and $0.02 \mathrm{U} / \mathrm{L}$ Taq DNA polymerase. First PCR was performed in thermal cycler starting with a pre-incubation at $94^{\circ} \mathrm{C}$ for three minutes, followed by 40 PCR cycles of one minute denaturation at $94^{\circ} \mathrm{C}$, one minute annealing at $58^{\circ} \mathrm{C}$, one minute elongation at $72^{\circ} \mathrm{C}$. The first PCR product was added to a new reaction mixture. Compositions and PCR cycles were same as the first PCR. Second PCR product was electrophoresed on a 3\% agarose gel. As a result, the specific PCR product of $T$. gondii was obtained from the extract from paraffin-embedded tissue sections of the bone marrow biopsy (Figure 2). AntiT. gondii therapy consisting of pyrimethamine, clindamycin, and leucovorin had been started. After sulfadiazine desensitization, clindamycin was replaced with sulfadiazine. Together with this, although our patient was negative on frequent PCR assay for tuberculosis, antitubercular treatment had been continued due to suspected tuberculosis from MRI. According to this, his fever was improved, but other clinical symptoms remained. Finally, anti- $T$. gondii therapy consisting pyrimethamine, sulfadiazine, and leucovorin plus prednisolone had an effect on improving his clinical symptoms and he was referred to other hospital in his home city at his request. 


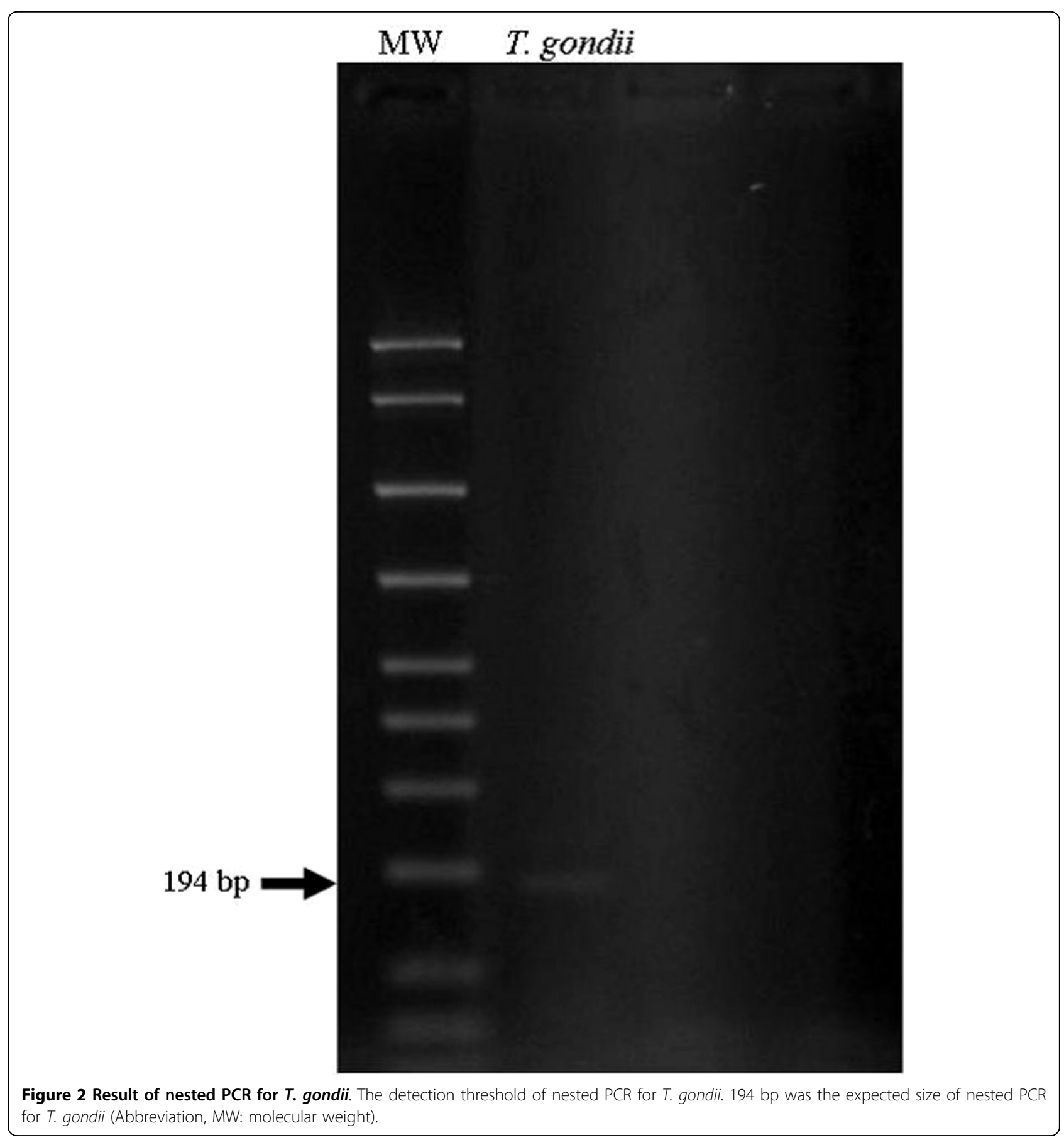

\section{Discussion}

Toxoplasmosis can be a life-threatening disease when it occurs in patients with HIV infection with decreased CD4 positive lymphocytes [7]. In particular, encephalitis is the most common toxoplasmic complication in such individuals [8]. It has been reported that the incidence of toxoplasmic meningioencephalitis ranges from 3 to $50 \%$ [9]. However, in Japan, the latest study reported that only $1.07 \%$ of patients with HIV develop toxoplasmosis [10] and the seroprevalence of IgG anti-toxoplasma antibodies in Japanese patients was less than $10 \%[11,12]$. Therefore, as toxoplasmic meningitis in patients with HIV infection is extremely rare, purulent or tuberculous meningitis should be considered initially as a disease for differential diagnosis. In our case, neither CSF examinations nor MRI of the brain were typical for toxoplasmosis. Failure of our patient's symptoms to respond to anti-bacterial and anti-tubercular treatment led us to perform bone 
marrow biopsy to search for another cause of generalized opportunistic infection. Histopathological findings from bone marrow biopsy suggested toxoplasmosis because the evidence of clustered micro-calcifying granules, but this finding was not adequate to diagnose the disease definitively. Therefore, to make the diagnosis, we employed a PCR assay using nucleic acid extracted from formalin-fixed and paraffin-embedded tissue section of the bone marrow. A major and classical diagnostic procedure for toxoplasmosis has been constituent with both serological tests and histopathological examinations [1], but these methods have limitations. In particularly, serological tests often fail to detect $T$. gondii infection in patients with HIV infection due to their decreased functioning of immunoglobulin production [13]. Recently, several PCR assays have been developed with different gene targets. Among them, a detection of T. gondii DNA has been regarded as one of the useful diagnostic procedures [1]. Furthermore, the potential of PCR assay to detect $T$. gondii in CSF has been previously reported, in which the sensitivity and specificity were described between 44 and $100 \%, 94$ and $100 \%$, respectively [9]. PCR assay using CSF could be successful to detect gene form T. gondii. However, to avoid an invasive diagnostic procedure we employed a PCR assay using nucleic acid extracted from the paraffin-embedded sections, which also had revealed strongly suggestive alterations for the toxoplasmosis. Although there was only a report that referred to PCR assay using nucleic acid extracted from paraffin-embedded tissue sections and this method has not been validated until now [14].

\section{Conclusions}

We wish to emphasize the usefulness of PCR assay using nucleic acid extracted from paraffin-embedded tissue sections processed for routine histopathological examination, if the section shows the infectious agents or findings suggesting some infectious diseases.

\section{Additional material}

Additional file 1: Primers of nested PCR for $T$. gondii.

\begin{abstract}
Abbreviations
CSF: cerebrospinal fluid; CT: computed tomography; HAART: highly active anti-retroviral therapy; HIV: human immunodeficiency virus; lgG: immunoglobulin G; MRI: magnetic resonance imaging; PCR: polymerase chain reaction.
\end{abstract}

\section{Consent}

Written informed consent was obtained from the patient for publication of this case report and any accompanying images. A copy of the written consent is available for review by the Editor-in-Chief of this journal.

\section{Competing interests}

KS reports received research grants from Pfizer Japan Inc., Janssen Pharmaceutical K.K., and Dainippon Sumitomo Pharma Co. All authors declare that they have no competing interests.

\section{Authors' contributions}

YO, conceptualized the case report, integrated the data, and wrote the manuscript as a major contributor; MS, carried out the HE stain, Von Kossa's stain, immunohistochemical staining and PCR assay; SY, contributed to management of the patient; HN, MW, TH, AM, and TH, carried out the histopathologic evaluation and revised histopathological description; KS, and ZY, assisted PCR assay; KS, gave final approval to the manuscript as a corresponding author. All authors contributed to conceptualizing and writing this case report.

\section{Acknowledgements}

This work was supported by the Health Science Research Grants for Research on Emerging and Re-emerging Infectious Diseases (H16-Shinko-6 and H19-Shinko-8), Measures for Intractable Diseases (H20 nannchi ippann 35) from Ministry of Health, Labour and Welfare of Japan, and by Grant of the Strategic Basis on Research Grounds for Non-governmental Schools at Heisei 20th from Ministry of Education, Culture, Sports, Science and Technology-Japan to K.S and Toho University project grant \#21-24 to Y.O.

\section{Author details}

${ }^{1}$ Department of Surgical Pathology, Toho University School of Medicine, 6-11-1 Omori-Nishi, Ota-Ku, Tokyo, 143-8541, Japan. ${ }^{2}$ Department of Infection Control, Toho University Medical Center, Omori Hospital, 6-11-1 Omori-Nishi, Ota-Ku, Tokyo, 143-8541, Japan.

Received: 16 November 2009 Accepted: 11 August 2010 Published: 11 August 2010

\section{References}

1. Dubey JP: The history of Toxoplasma gondii-the first 100 years. J Eukaryot Microbio 2008, 55:467-475.

2. Boothroyd JC, Grigg ME: Population biology of Toxoplasma gondii and its relevance to human infection: do different strains cause different disease? Curr Opin Microbiol 2002, 5:438-442.

3. Petersen E: Toxoplasmosis. Semin Fetal Neonatal Med 2007, 12:214-223.

4. Kasper L, Courret N, Darche S, et al: Toxoplasma gondii and mucosal immunity. Int J Parasitol 2004, 34:401-409.

5. Correa D, Cañedo-Solares I, Ortiz-Alegría LB, Caballero-Ortega H, RicoTorres CP: Congenital and acquired toxoplasmosis: diversity and role of antibodies in different compartments of the host. Parasite Immunol 2007, 29:651-660.

6. Tachikawa N, Goto M, Hoshino Y, et al: Detection of Toxoplasma gondii, Epstein-Barr virus, and JC virus DNAs in the cerebrospinal fluid in acquired immunodeficiency syndrome patients with focal central nervous system complications. Intern Med 1999, 38:556-562.

7. Nissapatorn V, Lee C, Quek KF, Leong CL, Mahmud R, Abdullah KA: Toxoplasmosis in HIV/AIDS patients: a current situation. Jpn J Infect Dis 2004, 57:160-165

8. Barbosa CJ, Molina RJ, de Souza MB, et al: Disseminated toxoplasmosis presenting as sepsis in two AIDS patients. Rev Inst Med Trop Sao Paulo 2007, 49:113-116.

9. Goto M, Takahashi T, Kanda T, Iwamoto A: Detection of Toxoplasma gondii by polymerase chain reaction in cerebrospinal fluid from human immunodeficiency virus-1-infected Japanese patients with focal neurological signs. J Int Med Res 2004, 32:665-670.

10. Kano S, Genka I, Yoshida K: Parasitic disease complicated with HIV/AIDS patients in Japan. Clinical Parasitology 2004, 15:95-98, (in Japanese).

11. Naito T, Inui A, Kudo N, et al: Seroprevalence of IgG anti-toxoplasma antibodies in asymptomatic patients infected with human immunodeficiency virus in Japan. Intern Med 2007, 46:1149-1150.

12. Yamaoka M, Konishi E: Prevalence of antibody to Toxoplasma gondii among inhabitants under different geographical and climatic conditions in Hyogo Prefecture, Japan. Jpn J Med Sci Biol 1993, 46:121-129. 
13. Porter SB, Sande MA: Toxoplasmosis of the central nervous system in the acquired immunodeficiency syndrome. N Engl J Med 1992, 327:1643-1648.

14. Tsai MM, O'Leary TJ: Identification of Toxoplasma gondii in formalin-fixed, paraffin-embedded tissue by polymerase chain reaction. Mod Pathol 1993, 6:185-188.

doi:10.1186/1752-1947-4-265

Cite this article as: Okubo et al:: Diagnosis of systemic toxoplasmosis with HIV infection using DNA extracted from paraffin-embedded tissue for polymerase chain reaction: a case report. Journal of Medical Case Reports 2010 4:265.

Submit your next manuscript to BioMed Central and take full advantage of:

- Convenient online submission

- Thorough peer review

- No space constraints or color figure charges

- Immediate publication on acceptance

- Inclusion in PubMed, CAS, Scopus and Google Scholar

- Research which is freely available for redistribution

Submit your manuscript at www.biomedcentral.com/submit
C Biomed Central 